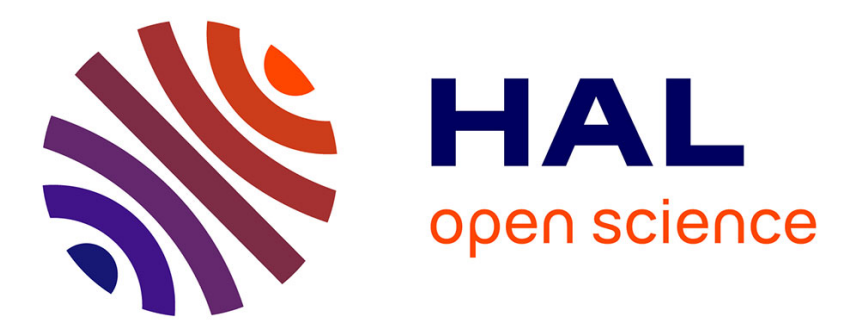

\title{
Measuring consumer perceptions for a better comprehension, specification and assessment of product semantics
}

Bernard Yannou, Jean-François Petiot

\section{To cite this version:}

Bernard Yannou, Jean-François Petiot. Measuring consumer perceptions for a better comprehension, specification and assessment of product semantics. International Journal of Industrial Ergonomics, 2004, 33 (6), pp.507-525. 10.1016/j.ergon.2003.12.004 · hal-00748737

HAL Id: hal-00748737

https://hal.science/hal-00748737

Submitted on 16 Mar 2013

HAL is a multi-disciplinary open access archive for the deposit and dissemination of scientific research documents, whether they are published or not. The documents may come from teaching and research institutions in France or abroad, or from public or private research centers.
L'archive ouverte pluridisciplinaire $\mathbf{H A L}$, est destinée au dépôt et à la diffusion de documents scientifiques de niveau recherche, publiés ou non, émanant des établissements d'enseignement et de recherche français ou étrangers, des laboratoires publics ou privés. 


\title{
Measuring consumer perceptions for the development of product semantics
}

\author{
Jean-François Petiot ${ }^{\mathrm{a}, *}$ Bernard Yannou $^{\mathrm{b}}$ \\ ${ }^{a}$ Institut de Recherche en Communications et Cybernétique de Nantes (UMR CNRS 6597), Ecole Centrale \\ de Nantes. 1, rue de la Noë, BP 92101, 44321 NANTES, France. \\ ${ }^{\mathrm{b}}$ Laboratoire Génie Industriel, Ecole Centrale Paris, Grande Voie des Vignes, 92295 Châtenay-Malabry, \\ France.
}

\footnotetext{
* Corresponding author:

Tel: Int +3324037 69 59Fax: Int +3324037 6930

E-mail address: Jean-Francois.Petiot@irccyn.ec-nantes.fr

URL: http://www.irccyn.ec-nantes.fr

Postal address: Ecole Centrale de Nantes, IRCCyN

1, rue de la Noë, BP 92101

44321 NANTES Cedex 3 France
} 


\begin{abstract}
Product semantics, the "study of the symbolic qualities of man-made forms in the context of their use, and application of this knowledge to industrial design" (Krippendorff and Butter, 1984) is an important challenge in product design. Because of subjectivity, this particular dimension of the user's need is difficult to express, to quantify and to assess. This paper presents a general approach to assess product semantics in a sound way. It is based on users' tests, and involves several classical methods in marketing and decision-making theory, as multidimensional scaling, semantic differential method, factor analysis, pairwise comparison and Analytical Hierarchy Process. As a result, our integrated approach provides designers with a tool which helps understand and specify the semantic part of the need; it rates and ranks the new product prototypes according to their closeness to the specified "ideal product", and it underlines the particular semantic dimensions that should be improved. To illustrate our approach, we have performed users' tests and applied our methodology to the design of table glasses. For the sake of clarity, each stage of the methodology is presented in detail on this particular example.
\end{abstract}

\title{
Relevance to industry
}

Our integrated framework of product semantics can be readily deployed in companies and used at different stages of the designing of new products. On the one hand, databases can be built and regularly updated to describe the perceptual space of a market segment. On the other hand, this database can be used to specify target requirements for a new product by simple qualitative comparisons to existing products in the database. Finally, emerging product concepts may be directly assessed with regards to the database and the requirements in a simple qualitative and comparative way.

Keywords: Product semantics, multidimensional scaling, semantic engineering, pairwise comparison, AHP, design assessment and selection 


\section{Introduction}

In today's highly competitive market, developing new products that meet possible consumers' needs as well as their tastes is a crucial issue in product design. To improve attractiveness, a well-designed product should not only satisfy requirements, defined objectively, but should also satisfy consumers' psychological needs, by essence subjective. In order to predict the success of a product, to control and to optimize its performances, one has to make explicit both sides of the need, subjective and objective. Both aspects of the need are considered in value analysis through the definition of usage functions (objective), esteem and aesthetics functions (subjective) (Aoussat et al., 2000), and in industrial design by the concepts of denotation and connotation (Quarante, 2001).

A lot of systematic methods (Pahl and Beitz, 1984; Suh, 1993), dealing mainly with usage functions, have been developed in engineering design to obtain successful products. These methods are efficient to assess and validate product prototypes with a scientifically based argumentation.

But there is a lack of such a methodology when one addresses esteem and aesthetic functions (brand image, personal aesthetics, current trends or fashion). Thus, form design or styling activities are often reduced to a discussion based on opinion and subjectivity, with no theoretical basis (Warrel, 2001). For example, the perception of the shape of a product is often nothing but a style of design, depending much more on the designer's taste than on real customers' trends, as some studies clearly showed (Hsu et al., 2000). The understanding of the links between the product characteristics and the meaning of the product is still low. The difficulty lies in the fact that the user's feeling of a product is a very complex cognitive process and many intricate factors contribute to the perception mechanisms. Furthermore, a global model of user's perception should establish links between two kind of variables, very different in essence: i.e the "subjective quality", relative to the assessment of consumer, and controlled by the subject's perceptions; and the "design elements", represented by the physical characteristics which define the product (Brunswick, 1952). Taking the perception for product design into account still remains a challenge. Two main research trends tackle this problem.

In the field of industrial design, researches in product semantics intend to understand how we as human beings interpret the appearance, the use and the context of a product (Krippendorff and Butter, 1984). Taking the product as a communication media between the designer and the user, product semantics tries to explain which messages a product expresses or represents.

Various scientific approaches have been gathered by Japanese researchers under the name Kansei Engineering. This research aims at exploring the structure of emotions by building a data base on consumer feelings. From the consumer's point of view, a forward mapping process from perceptual words to design elements is established, and from the designer's point of view, a backward process from drawings to perceptual words is proposed (Nagamachi, 1995 and 2002). Some methods of category classification based on the Semantic Differential Method (SDM) have been used for the design of car interiors for example (Jindo and Hirasago, 1997). More sophisticated methods based on genetic algorithms, neural networks or fuzzy logic have been applied to ensure mappings between perceptual words and design elements, but these systems are often opaque for designers and consumers. A semantic transformation method for automotive form design is proposed in (Hsiao and Wang, 1998), allowing an automatic regulation of the shape with respect to the image required.

In this context, so as to ensure the development of product semantics in a more rational and scientific way, we are proposing a methodology which takes users' perception into account. It combines methods and techniques derived both from engineering design and marketing. From engineering methods, we keep the fact that users' needs are expressed ahead of design 
specifications, and that design solutions or concepts are assessed according to evaluation criteria. From marketing, we use techniques which allow to comprehend users' perceptions and to grasp consumers' feelings and appraisal.

Our methodology addresses the four following design stages, in an integrated manner:

1. Understanding the need related to product semantics

2. Finding relevant criteria to characterize and express the need

3. Specifying the requirements of a new product

4. Assessing the performances of new solutions

This work is motivated by the fact that there still remains a gap between designers' and users' perceptions, due to the fact that subjective functions and criteria are often neither named nor objectively assessed (Hsu et al., 2000). Furthermore, design being a pluri-disciplinary activity, it requires collaboration and interactions between many design team members. Formulating product semantics serve as communication medium between the actors of a team, and will then increase the accuracy and the rigor of the exchanges within a company.

In section 2, we briefly present the basic methods our methodology is based upon. Section 3 makes an overview of the 8 stages of our methodology and of the data flow. Section 4 is the most important one, in which a particular example is described in detail. Section 5 discusses the results and the practical use of this methodology for the assessment of products. In section 6 , a conclusion and perspectives are drawn.

\section{Backgrounds}

To study users'perceptions, researchers in marketing propose various methods (Kaul and Rao, 1995). Perceptual maps are commonly used to take perceptions into account and to control the product positioning. The basic idea is to build a multi-attribute perceptual space in which each product is represented by a point. Two main methods are used to build the perceptual space: the semantic differential method (SDM) and multidimensional scaling (MDS). In addition to these methods, we propose a short description of pairwise comparison techniques, which are relevant to grasp subjective assessments.

\subsection{Semantic Differential Method (SDM)}

Semantic differential method (SDM) (Osgood et al., 1957) consists in listing the semantic attributes of the product to analyze and carry out user-tests in which the user must assess the product according to these attributes. The attributes are often defined by pairs of antonymous adjectives which lie at either end of a qualitative scale. A semantic space, Euclidean and multidimensional, is then postulated. Factor analysis and Principal Components Analysis may be used to reduce the dimension of the space and to find the underlying dimensions. SDM is used for example for the analysis of families of products (Chuang et al., 2001) or for the design of a new product (Jindo and Hirasago, 1995; Hsu et al., 2000).

\subsection{Multidimensional scaling (MDS)}

Multidimensional scaling uses dissimilarity assessments to create a geometrical representation of the perceptual space related to a family of objects. This method, initially developed for psychometric analysis (Shepard et al., 1972), is a process whereby a distance matrix among a set of stimuli is translated into a representation of these stimuli within a perceptual space. Taking all the possible pairs of stimuli (here pairs of products) into account, each subject evaluates their degree of similarity on a quantitative scale. Technically, the MDS technique amounts to locating the products considered as points in a $k$-dimensional space such that the Euclidean distances between them correspond to the dissimilarities perceived in the 
input matrix as closely as possible. Dimension $k$ of the need space is the lowest dimension respecting an optimization criterion called stress, which represents the "poorness of fit". The main advantage of this method is that the tests are based on instinctive dissimilarity assessments, which do not set any criteria or predefined semantic scale. This method provides a space for a visualization of the perception of products. An application of MDS for the study of product semantic is presented in (Lin et al., 1996).

\subsection{Pariwise comparison (PC)}

Instead of assessing a particular score for the performance of a product on a scale in an absolute manner, the idea is to estimate the relative importance of the scores of some pairs of products (most of the time the scores ratio) under a given criterion. A ratio scale must be defined for each criterion (Stevens, 1946). This leads to a pairwise comparison (PC) matrix, which can be processed to extract a realistic normalized vector of scores. Pairwise comparisons are known to be easily administrated because decision makers (DMs), or customers assessing the products in our case, only focus on a pair of products and on a criterion instead of brutally facing the whole multi-attribute issue. So as not to compel DMs to fill the overall PC matrix as in the well known eigenvector method (Saaty and $\mathrm{Hu}$, 1998), we used the Least Squares Logarithmic Regression (LSLR) PC method proposed by (De Graan, 1980) and (Lootsma, 1981). Sparse PC matrices are then tolerated, which is preferable for the relative assessment of numerous products (more than eight). Once the scores are attributed for the products under a set of decision criteria, an additional PC assessment between the criteria themselves results in a weight vector for the criteria. Next, the Analytical Hierarchy Process (Saaty, 1980) method merely consists in calculating global rates for the products by the weighted sum of the product scores under the criteria by the criteria weights. Despite a number of known shortcomings, among which a difficulty to interpret the meaning of score scales and of the weight ratios (Belton, 1986), the AHP is considered as a valuable method for selecting a preferred alternative in a short-list where no obvious objective means of measurement and obvious objective function exist, and we are in the presence of a wealth of information and interpretation. This situation is exactly that of our design selection issue. In addition, the PC methods provide a measure of judgment inconsistency, allowing the DMs to highlight their personal misunderstandings or imprecisions and consequently to enter a virtuous loop to improve the quality of assessment (Yannou, 2002). An integration of AHP in a design method for developing new products is described in (Hsiao, 2002).

\section{Brief overview of the stages of our methodology}

In order to assess product semantics, we propose a methodology split up into several stages, each of them including users' tests performed by a panel of subjects. Here is a brief description of its stages:

1. Definition of the semantic attributes. The starting point is a set of representative existing products which all answer the same usage functions, but differ from a perception point of view. Subjects are asked to describe their perceptions about the product freely. A list of $N$ relevant semantic criteria is extracted from these descriptions.

2. Determination of the perceptual space. So as to grasp the perceptual differences between products, the Multidimensional Scaling Method (MDS) is used to build a $K$-dimensional ( $K$ $\leq N-1$ ) Euclidean perceptual space, in which all the products are located. Several perceptual dimensions $X k_{i} ; i=1,2, \ldots, K$, are found and a visual clustering of products can be observed.

3. Raw determination of the semantic space. So as to investigate the subjects' perception of a product and to explain the reasons for product differentiations, the Semantic Differential Method (SDM) is used, with the list of semantic criteria established in stage 1. A principal component analysis (PCA) is performed on the raw data of the SDM. The role of PCA is first to detect pairs of adjective perceived as synonyms, in order to reduce the dimension of 
the semantic space (some adjectives are highly correlated and underlying dimensions are revealed), and secondly to find out which pairs of adjective contribute very little into the variance of the assessments. Such pairs are designed as irrelevant for a description of the semantics of the given set of products. This produces the definition of a sub-list of relevant semantic attributes $X r_{i} ; i=1,2, \ldots, R$, which are relevant to assess the product semantics.

4. Fine determination of the semantic space. From this reduced list of semantic attributes, a finer multi-criteria comparison of products is performed by the subjects. With the help of an inner LSLR Pairwise Comparison (PC) method (De Graan, 1980), the products are weighted under each semantic attribute (giving the scores), more precisely than in SDM.

5. Definition of the semantic part of the need. The need related to a new product is specified in two ways. First, a positioning of the product is proposed in the perceptual space. The idea is similar to product positioning strategies in marketing, where perceptual maps are used for product cannibalization or competitive positioning (research of new market). Next, the specifications of a new product, named the "ideal product", are achieved by Pairwise Comparisons relatively with the set of existing products. In addition to the description of this ideal product, the need for the targeted market segment is also expressed by the determination of weights of the semantic attributes with the aid of the Pairwise Comparison technique.

6. Design stage. Starting from the specifications, new potential product solutions are devised.

7. Assessment of the potential products. The scores of the new potential products are assessed under the semantic attributes by pairwise comparisons (see stage 4) relatively to the existing products.

8. Rating of the products. Given the assessment of each product according to the evaluation criteria, the products are rated according to their distance to the "ideal" product, through a conventional AHP procedure.

\section{A case study: Table glasses}

We have applied the above methodology to the assessment of glasses, which are very interesting products from a semantic and esteem/aesthetic point of view. A study on such products (wine-glass) was proposed in (Matsuoka, 1999) where the authors presented a method for form generation. For our study, we have imagined a company, which makes a range of glasses (pictures and shapes given figure 1), and wants to design a new glass in order to diversify its products portfolio. In the following paragraph, we are proposing to show how our method can be used to assess in a solid way product semantics of several design solutions.

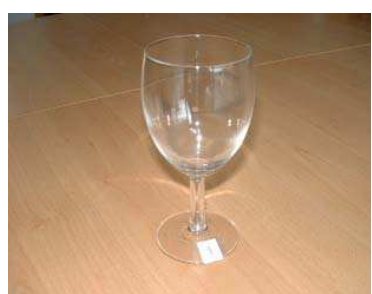

1

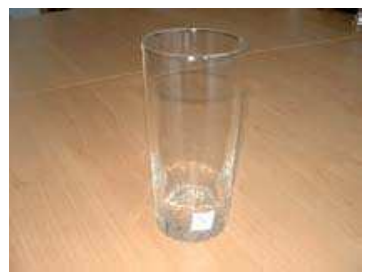

5

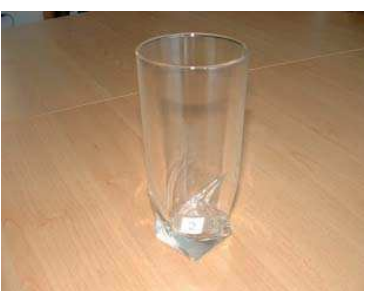

2

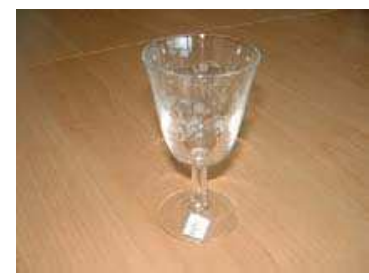

6

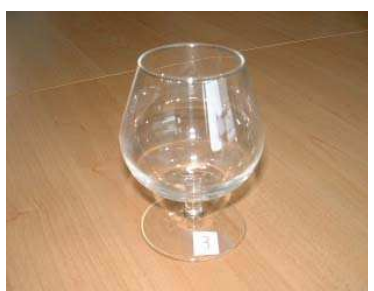

3

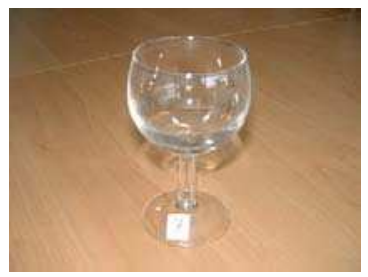

7

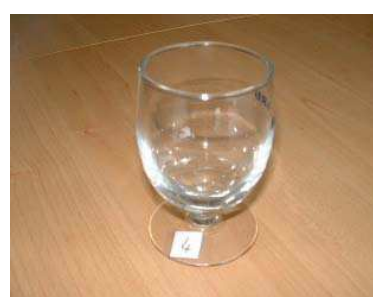

4

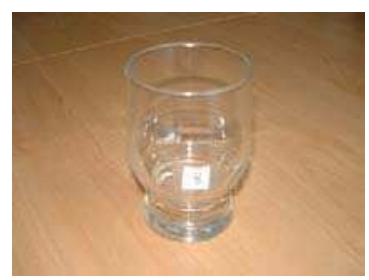

8 


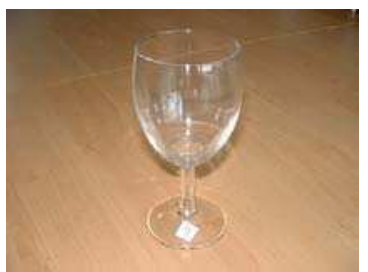

9

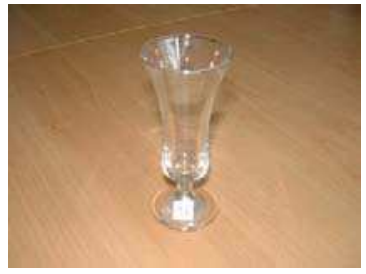

13

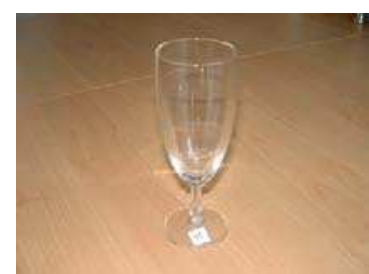

10

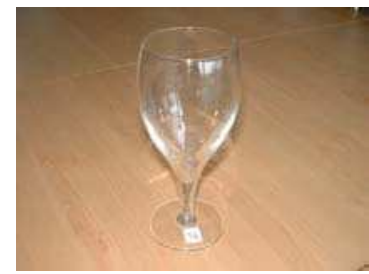

14

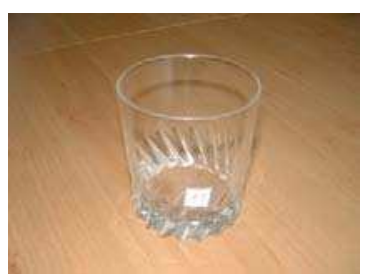

11

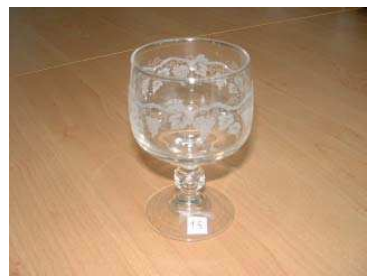

15

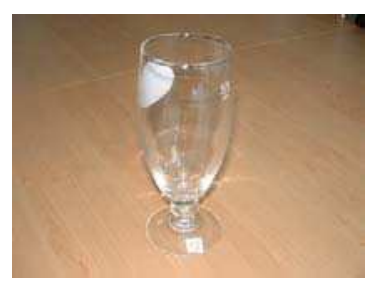

12

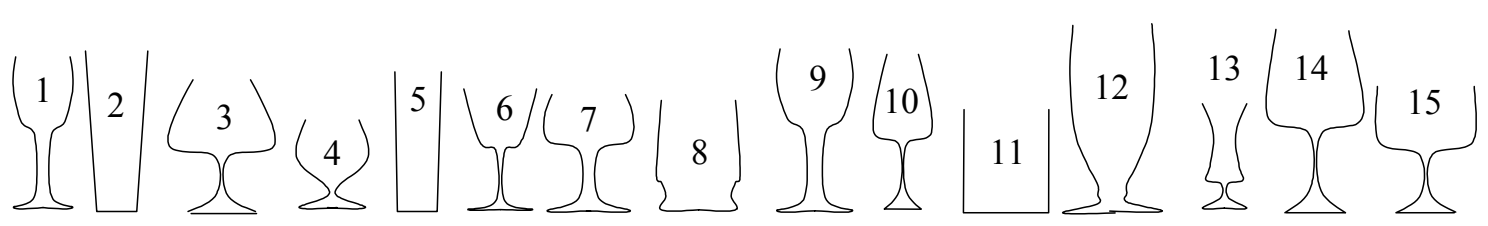

Fig. 1. Pictures and shapes of the 15 glasses proposed for the study.

\subsection{Extracting semantic attributes}

The 15 glasses have been physically proposed to 11 subjects (10 males, 1 female) for a detailed evaluation. Subjects were asked to verbally express various characteristics of their perceptions of the glasses. An analysis of their descriptions and of the most frequently occurring characteristics has led to the setting up of 17 pairs of adjective (v1 to v17) (table 1).

Table 1

The 17pairs of adjective proposed by the subjects, and used in the SDM test.

\begin{tabular}{|ccc|}
\hline v1: Traditional-modern & v7: Common particular & v13: Unoriginal-creative \\
v2: Easy for drinking/not... & v8: Easy to fill-not... & v14: Existing-new \\
v3: Decorative-practical & v9: Flashy-discreet & v15: Good perceived quality- \\
v4: Unstable/stable & v10: Multiusage-occasional & bad... \\
v5: Masculine-feminine & v11: Easy to handle-not... & v16: Strong -fragile- \\
v6: Complicated-simple & v12: Classy-vulgar & v17: Coarse-delicate \\
\hline
\end{tabular}

\subsection{Building of the perceptual space with $M D S$}

In order to obtain the subjects' dissimilarity matrix, we have used a convenient technique which can be easily administered. It consists in sorting the products into piles. For each pair of glasses, subjects were asked to sort the products into mutually exclusive groups based on their similarities. No constraint was given on the number of classes to make. The assumption underlying this method is that products occurring in the same group are more similar than products occurring in different groups (Popper and Heymann, 1996). The sorting data for any subject consists of a matrix of 0 and 1, indicating whether the subject grouped two glasses together or not. Individual dissimilarity matrices are then summed for all subjects, leading to the group's dissimilarity matrix. Here, one assumes, for the time being, that the group members behave in a somewhat similar manner, i.e. we do not deal with clustering considerations of the group. With this matrix as the input, non metric MDS has been used to calculate the perceptual 
coordinates of the glasses. A 2-dimensional configuration, with a stress value equal to 0.1 (considered as a correct "poorness of fit") has been retained (figure 2).

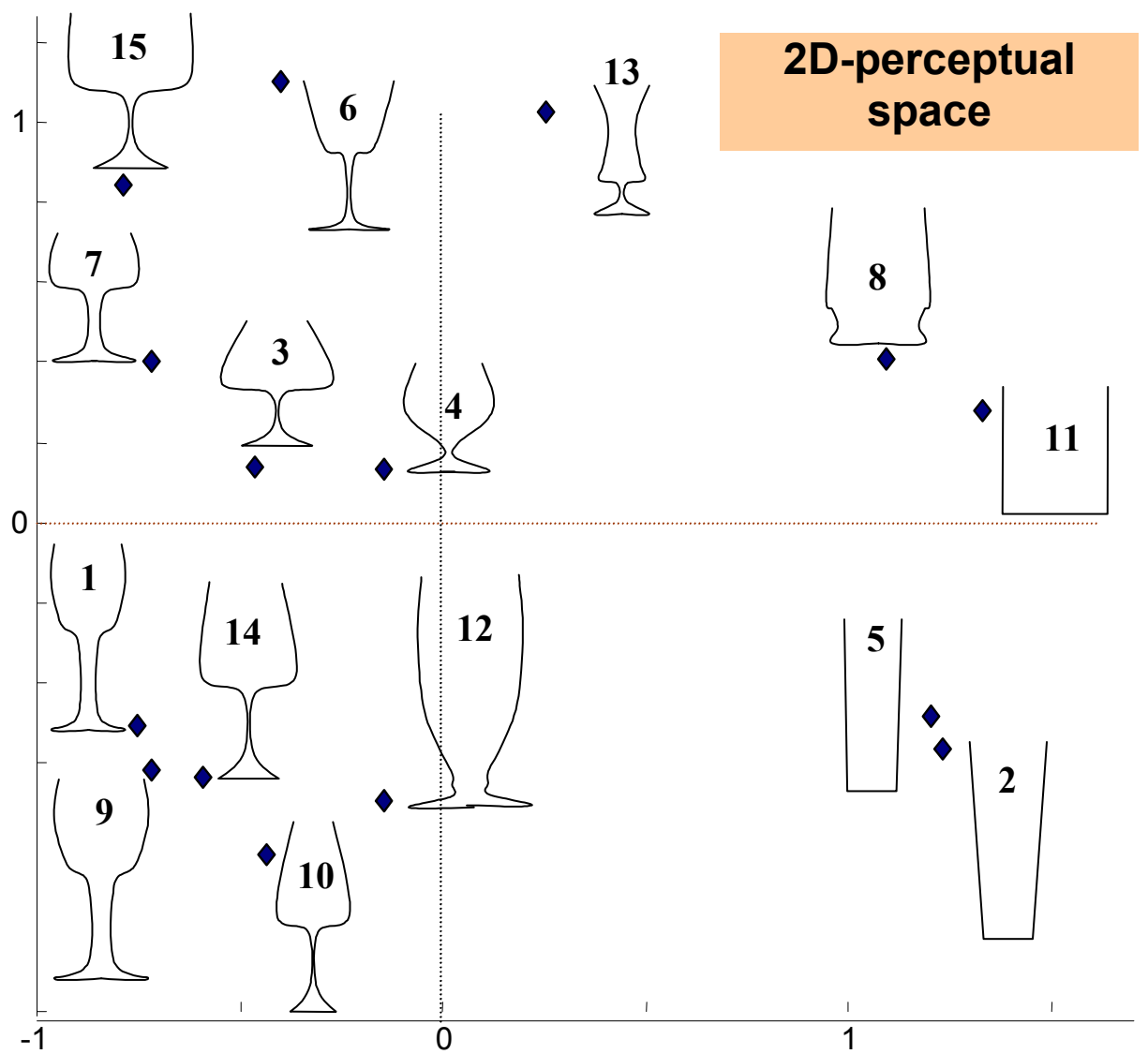

Fig. 2. Position of the glasses in the perceptual space.

\subsection{Raw determination of the semantic space with SDM}

Subjects were asked to assess each glass on a 7 levels Likert scale (figure 3) according to the list of pairs of adjectives proposed in table 1 .

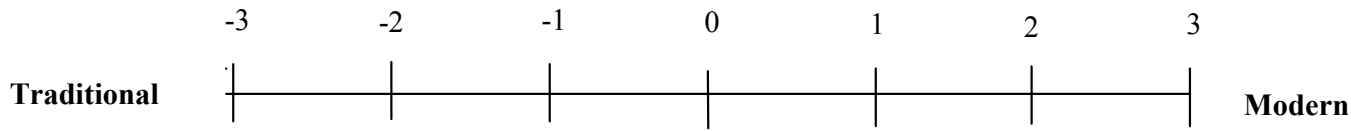

Fig. 3. Scale for the assessment of the pair of adjectives Traditional-Modern.

A cluster analysis was performed on these data in order to find a panel as homogeneous panel as possible. One subject, whose assessment was very different ${ }^{1}$ from the rest of the group's, was removed. We then calculated the average of the assessment for 10 subjects only. A principal component analysis on the average data allowed the research of underlying dimensions of the semantic space (figure 4). Axis 1 and 2 respectively account for $64 \%$ and $17 \%$ of the variance. So, $91 \%$ of the variance is considered in a two-dimensional factorial space. Each pair of adjectives is represented in the factorial space by a "vector", the scalar product between 2 vectors being the correlation coefficient between 2 pairs of adjectives. After an analysis of the correlations between pairs of adjectives (colinearity of the vectors), and a study

\footnotetext{
${ }^{1}$ The subject's understanding of the meaning of several pairs of adjectives was the opposite of the group's.
} 
of the meaning of the adjectives, we have extracted a minimal list of semantic attributes (table 2). For example, pairs of adjectives v16 (strong-fragile), v5 (masculine-feminine) and v17 (coarse-delicate) have been merged because they are highly correlated (see figure 4), and they are furthermore closely related. Of course this merging requires that the candidate pairs of adjectives be semantically close (or synonyms) in addition to a proven correlation. Indeed, that would be a source of confusion to group together under a same semantic component different semantic pairs which are correlated only for the given products, such as v2 (easy for drinking/not...) and v5 (masculine-feminine).

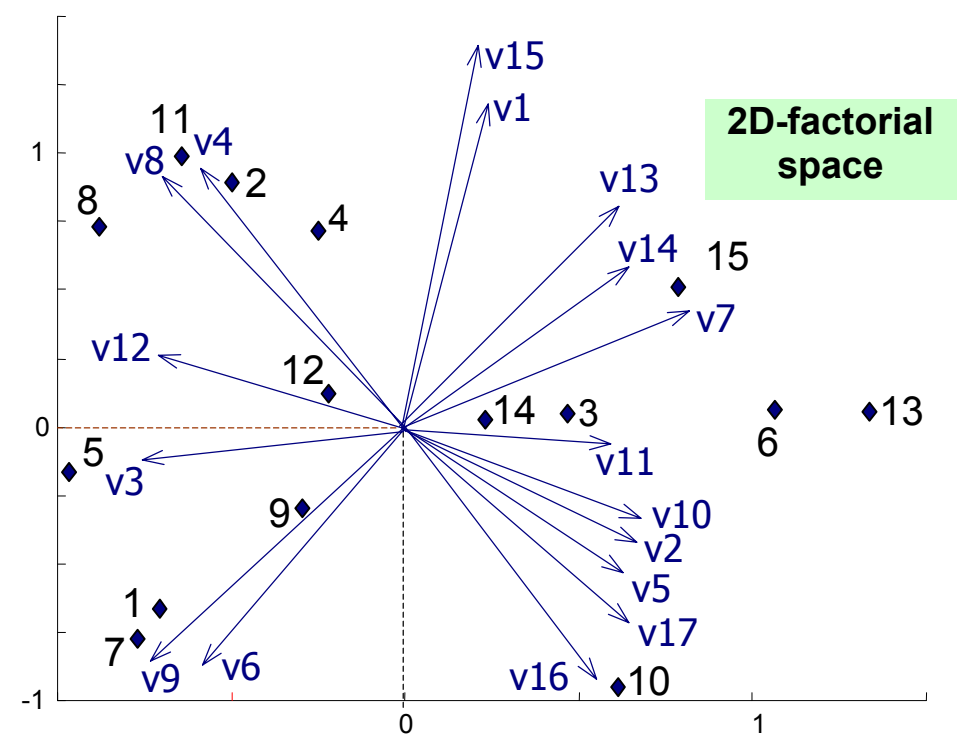

Fig. 4. Positions of the glasses and the pairs of adjectives in the factorial space

Table 2

The 17 pairs of adjectives used in the SDM test, and their corresponding semantic attributes

\begin{tabular}{|c|c|}
\hline Semantic attribute & Semantic attribute \\
\hline $\begin{aligned} \text { v1: Traditional-modern } & \longrightarrow \text { Modernity } \\
\text { v2: Easy for drinking/not... } & \longrightarrow \text { Ease of drinking with } \\
\text { v3: Decorative-practical } & \longrightarrow \text { Decorativeness } \\
\text { v4: Unstable/stable } & \longrightarrow \text { Stability } \\
\text { v6: Complicated-simple } & \longrightarrow \text { Simplicity } \\
\text { v10: Multiusage-occasional } & \longrightarrow \text { Ordinariness } \\
\text { v8: Easy to fill-not.... } & \longrightarrow \text { Ease of filling } \\
\text { v9: Flashy-discreet } & \longrightarrow \text { Showiness } \\
\text { v11: Easy to handle-not... } & \longrightarrow \text { Ease of handle }\end{aligned}$ & $\begin{aligned} & \text { v12: Classy-vulgar } \longrightarrow \text { Smartness } \\
& \text { v7: Common-particular } \\
& \text { v13: Unoriginal-creative } \longrightarrow \text { Originality } \\
& \text { v14: Existing-new } \\
& \text { v15: Good perceived } \longrightarrow \text { Quality } \\
& \text { quality-bad... } \\
& \text { v16: Strong-fragile } \\
& \text { v5: Masculine-feminine } \longrightarrow \text { Fragility } \\
& \text { v17: Coarse-delicate }\end{aligned}$ \\
\hline
\end{tabular}

\subsection{Fine determination of the semantic space}

Now that a minimal list of relevant semantic attributes has been established, semantic attributes are assessed more precisely with pairwise comparison tests. By this process, for each attribute, a percentage of $100 \%$ of importance is shared among the set of 15 glasses. In practice, each of the $S=10$ subjects is asked to fill 30 pairwise comparisons in each of the $R=13$ comparison matrices (corresponding to semantic attributes, see an example in figure 5) of $15 \times 15$ size (for $N=15$ products) on a 7 -levels scale $(<<,<,<\sim,=,>\sim,>,>>)$.

The subjects had the complete choice of the 30 comparisons to fill in the $N .(N-1) / 2=105$ potential comparisons of the superior half of the PC matrix. Nevertheless, so as to have computable data, we imposed the constraint that each product should be involved in at least one comparison. 
For example, the questionnaire sheet for the pairwise comparison matrix for semantic attribute "originality" is given in figure 5.

One advice was to target one or two particular products that are very expressive concerning the given semantic attribute and that could be compared with evidence to others. In figure 5 for example, these products are \#11 and \#4.

\begin{tabular}{|c||c|c|c|c|c|c|c|c|c|c|c|c|c|c|}
\hline \multicolumn{10}{|l|}{ Name: } & \multicolumn{10}{|c|}{} \\
\hline \hline originality & $\mathbf{2}$ & $\mathbf{3}$ & $\mathbf{4}$ & $\mathbf{5}$ & $\mathbf{6}$ & $\mathbf{7}$ & $\mathbf{8}$ & $\mathbf{9}$ & $\mathbf{1 0}$ & $\mathbf{1 1}$ & $\mathbf{1 2}$ & $\mathbf{1 3}$ & $\mathbf{1 4}$ & $\mathbf{1 5}$ \\
\hline \hline $\mathbf{1}$ & & & $<$ & & & & & $=$ & & $<$ & & & & \\
\hline 2 & & & $<<$ & $=$ & & & & & & $=$ & & & & \\
\hline 3 & & & & & & & $>$ & & & $<<$ & & & & \\
\hline 4 & & & & & $>>$ & & $=$ & $=$ & & $=$ & $=$ & $>>$ & $<\sim$ & \\
\hline 5 & & & & & & & $=$ & & & $=$ & & & & \\
\hline 6 & & & & & & & & & & $<<$ & $=$ & & & $=$ \\
\hline 7 & & & & & & & & & & $<\sim$ & & & & $>>$ \\
\hline 8 & & & & & & & & & & $=$ & & & & \\
\hline 9 & & & & & & & & & $=$ & $<$ & & & & \\
\hline 10 & & & & & & & & & & $<$ & & & & \\
\hline 11 & & & & & & & & & & & $>\sim$ & $>>$ & $<$ & $<<$ \\
\hline 12 & & & & & & & & & & & & & & \\
\hline 13 & & & & & & & & & & & & & & \\
\hline 14 & & & & & & & & & & & & & & \\
\hline
\end{tabular}

Fig. 5. Questionnaire sheet for one of the $R=13$ pairwise comparison matrices each subject has to fill.

Let us notice that a semantic attribute (as "originality") and the corresponding pair of adjectives (here v13 "unoriginal-creative") are not defined over the same type of measurement scale. Indeed, a pair of adjectives is defined over an interval scale (Stevens, 1946), i.e. a product is qualitatively located between what is considered as the most unoriginal and what is considered as the most creative. A difference of measure (interval) over this scale is meaningful, but there is little judgment of value, for the zero value does not exist. On the contrary, a semantic attribute must now be defined on a ratio scale so as to start the processes of pairwise comparisons and AHP notations (Saaty, 1980). A ratio scale requires a scale origin so as to get meaningful ratios. A difficulty occurs for the subjects to get a similar significance of the origin and of the ratio progression. This difficulty is mainly overcome by the adoption of a 7 levels scale (much less, less, slightly less, equal, slightly more, more, much more) noted $(<<,<,<\sim,=$, $>\sim,>,>>$ ), e.g. "the originality of product \#1 is slightly less than the one of product \#2". In practice, this semantic scale is indexed onto a numerical scale $(10 \%, 25 \%, 40 \%, 50 \%, 60 \%$, $75 \%, 90 \%$ ) corresponding to the estimation of the relative part of the score of product $i$ (on row $i$ ) over the sum of both scores of product $i$ and product $j$ (on column $j$ ). Let us note $c^{*}{ }_{i j}$ such a comparison on row $i$ and column $j$. Then, $c_{i j}^{*}$ is an estimation of the quantity $w_{i} /\left(w_{j}+w_{i}\right), w_{i}$ and $w_{j}$ standing for the scores for product $i$ and product $j$. Let us operate a transformation into score ratios such that:

$$
c_{\mathrm{ij}} \approx \frac{\mathrm{w}_{\mathrm{i}}}{\mathrm{w}_{\mathrm{j}}}=\frac{-1}{1-\frac{1}{\mathrm{c}^{*}{ }^{*}}}
$$

The Least Squares Logarithmic Regression (LSLR) PC method proposed by De Graan and Lootsma consists in minimizing the cumulated square distance between the logarithmic terms of 
the estimation of the score ratio $c_{i j}$ and of the actual score ratio $w_{i} / w_{j}$, distance given by the formula:

$$
\sum_{i=1}^{N} \sum_{j=i+1}^{N} \sum_{k=1}^{S_{i j}} \alpha_{i j k}\left(\log \left(c_{i j k}\right)-\left(\log \left(w_{i}\right)-\log \left(w_{j}\right)\right)\right)^{2}
$$

with $c_{i j k}, i=1,2, \ldots, N, j=1,2, \ldots, N, k=1,2, \ldots, S_{i j}$ the opinion of the $k^{\text {th }}$ subject for the $(i, j)$ comparison, $S_{i j}$ the number of subjects having expressed an opinion on $(i, j), S$ the number of subjects and $\alpha_{i j k}(i, j=1,2, \ldots, N, k=1,2, \ldots, S)$ a parameter equal to 1 when the $k^{\text {th }}$ subject decides to express a personal opinion $\left(c_{i j k} \in\left[0,+\infty[)\right.\right.$ and equal to 0 otherwise. When $\alpha_{i j k}$ equals $0, c_{i j k}$ is set to an arbitrary positive non zero value in order to ensure that $\alpha_{i j k} \log \left(c_{i j k}\right)=0$.

Minimization of (2) leads to the resolution of the so-called normal equations:

$$
\begin{aligned}
& \theta_{i} \sum_{j \neq i}^{N} S_{i j}-\sum_{j \neq i}^{N-1} S_{i j} \theta_{j}=\sum_{j \neq i}^{N} \sum_{k=1}^{S} \alpha_{i j k} b_{i j k}, \quad i=1,2, \ldots, N-1 ; \\
& \theta_{i} \approx \log \left(w_{i}\right), \quad i=1,2, \ldots, N, \\
& \theta_{N}=0, \quad(\text { weight fixed to } 1) \\
& b_{i j k}=\log \left(c_{i j k}\right), i, j=1,2, \ldots, N ; k=1,2, \ldots, S \\
& S_{i j}=\sum_{k=1}^{S} \alpha_{i j k}^{2}=\sum_{k=1}^{S} \alpha_{i j k}, i, j=1,2, \ldots, N \text { and } i \neq j \\
& S_{i j}: \text { number of opinions for comparison }(i, j)
\end{aligned}
$$

Since the scores are defined up to a multiplicative constant, the normal equations are underconstrained. Solving the system requires to set one of the scores to an arbitrary value $\left(w_{N}=1\right)$. Moreover, the possible missing opinions must not reduce the rank $(N-1)$ of the system of normal equations. This condition is satisfied when each element is involved in at least one opinion and when no pair of elements is disjoint by transitivity (elements $i$ and $j$ are disjoint by transitivity when $\left.\alpha_{i h k} \times \alpha_{h j k}=0 \quad \forall k=1,2, \ldots, S_{i j}, \forall h=1,2, \ldots, N\right)$.

The last stage consists in the normalization procedure described by the following formula:

$$
w_{\mathrm{i}}=\frac{\exp \left(\theta_{\mathrm{i}}\right)}{\sum_{j=1}^{N} \exp \left(\theta_{j}\right)}, i=1,2, \ldots, N
$$

The score vectors relative to the $R=13$ semantic attributes are collected in table 3 .

Table 3

Score vectors of the initial set of glasses

\begin{tabular}{|l|c|c|c|c|c|r|c|c|c|c|r|r|r|r|r|}
\hline \multicolumn{1}{|c|}{ Scores (\%) } & $\mathbf{1}$ & $\mathbf{2}$ & $\mathbf{3}$ & $\mathbf{4}$ & $\mathbf{5}$ & $\mathbf{6}$ & $\mathbf{7}$ & $\mathbf{8}$ & $\mathbf{9}$ & $\mathbf{1 0}$ & $\mathbf{1 1}$ & $\mathbf{1 2}$ & $\mathbf{1 3}$ & $\mathbf{1 4}$ & $\mathbf{1 5}$ \\
\hline Stability & 6,0 & 8,4 & 4,8 & 4,8 & 7,8 & 6,3 & 6,1 & 8,2 & 4,3 & 4,6 & 13,0 & 5,7 & 5,9 & 7,0 & 7,2 \\
\hline Fragility & 7,3 & 8,5 & 7,4 & 4,6 & 3,5 & 11,1 & 5,8 & 4,8 & 5,6 & 6,7 & 8,0 & 5,9 & 5,8 & 5,2 & 9,7 \\
\hline Quality & 6,0 & 8,2 & 4,8 & 8,3 & 5,6 & 7,5 & 8,8 & 6,1 & 4,9 & 4,6 & 6,9 & 7,0 & 4,6 & 6,3 & 10,6 \\
\hline Originality & 4,6 & 7,7 & 7,0 & 5,7 & 4,7 & 9,2 & 7,0 & 4,5 & 4,4 & 5,1 & 5,1 & 5,2 & 14,2 & 5,1 & 10,5 \\
\hline Smartness & 5,2 & 4,4 & 4,3 & 6,6 & 3,6 & 10,3 & 9,5 & 5,5 & 4,9 & 6,5 & 3,8 & 4,6 & 10,9 & 4,8 & 15,0 \\
\hline Ease of handle & 3,8 & 9,5 & 4,6 & 6,2 & 9,7 & 4,5 & 4,6 & 9,1 & 4,6 & 3,6 & 10,5 & 9,8 & 9,4 & 4,7 & 5,4 \\
\hline Ordinariness & 7,3 & 12,3 & 4,0 & 4,8 & 12,5 & 3,4 & 6,0 & 9,8 & 4,6 & 3,8 & 6,1 & 4,6 & 6,8 & 7,2 & 6,7 \\
\hline Ease of filling & 4,9 & 6,9 & 3,5 & 5,6 & 7,5 & 4,2 & 5,2 & 8,5 & 7,4 & 3,5 & 13,9 & 7,4 & 9,9 & 6,9 & 4,7 \\
\hline Showiness & 5,4 & 5,5 & 10,2 & 7,5 & 4,7 & 11,8 & 5,5 & 3,6 & 4,8 & 6,4 & 4,3 & 3,0 & 10,7 & 6,2 & 10,4 \\
\hline
\end{tabular}




\begin{tabular}{|l|r|r|r|r|r|r|r|r|r|r|r|r|r|r|r|}
\hline Simplicity & 7,4 & 9,1 & 5,8 & 6,7 & 10,4 & 7,6 & 6,4 & 7,2 & 5,6 & 4,9 & 4,1 & 4,5 & 7,0 & 5,4 & 7,7 \\
\hline Decorativeness & 6,3 & 5,5 & 5,5 & 5,9 & 4,1 & 8,6 & 5,8 & 5,2 & 4,1 & 8,3 & 4,6 & 7,9 & 12,1 & 3,9 & 12,3 \\
\hline Ease of drinking with & 4,4 & 7,4 & 5,2 & 6,0 & 8,5 & 6,3 & 4,6 & 7,5 & 5,5 & 4,2 & 11,5 & 6,2 & 4,4 & 7,2 & 11,3 \\
\hline Modernity & 8,5 & 3,5 & 8,0 & 6,7 & 3,5 & 6,2 & 6,0 & 3,4 & 3,7 & 6,3 & 3,9 & 4,1 & 13,7 & 10,1 & 12,3 \\
\hline
\end{tabular}

Limayem and Yannou (Limayem, 2001; Yannou, 2002) have proposed a set of consistency indicators allowing the subjects to measure and improve on the one hand their own judgmental consistency and on the other hand the group's.

Let us say, to make it short, that a consistency indicator assesses the numerical consistency between the comparison assessments which are redundant information. It measures the respect of the transitivity condition: $\left.c_{i h x} \cdot c_{h j y}=c_{i j z} ; i, j, h=1,2, \ldots, N ; x, y, z=1,2, \ldots, S\right)$ and, schematically, this is a function of the objective given in formula (2). The consistency indicator varies from 0 (total inconsistency) to $100 \%$ (perfect consistency). An unsatisfactory consistency (here less than $75 \%^{2}$ ) reveals a confuse idea, a lack of knowledge, a fuzzy preference model, an intransitive behavior, and so on. In the PC matrix, a fixed number of expected comparisons was asked to the subject, in order to allow to compare the consistency indicators of the different matrices, and after averages, of the consistency levels of subjects and semantic attributes.

The consistency indicators for the subjects and for the group are given in table 4 . These indicators will be used afterwards in stage 8 .

Table 4

Consistency indicators for the PC

\begin{tabular}{|l|c|c|c|c|c|c|c|c|c|c|c|}
\hline $\begin{array}{c}\text { Consistency } \\
\text { indicators (\%)/ } \\
\text { subjects }\end{array}$ & $\mathbf{1}$ & $\mathbf{2}$ & $\mathbf{3}$ & $\mathbf{4}$ & $\mathbf{5}$ & $\mathbf{6}$ & $\mathbf{7}$ & $\mathbf{8}$ & $\mathbf{9}$ & $\mathbf{1 0}$ & average \\
\hline Stability & 76 & 85 & 99 & 86 & 85 & 87 & 95 & 97 & 95 & 51 & $85 \%$ \\
\hline Fragility & 78 & 79 & 88 & 89 & 90 & 84 & 94 & 69 & 91 & 90 & $85 \%$ \\
\hline Quality & 80 & 73 & 90 & 93 & 94 & 82 & 98 & 92 & 85 & 67 & $85 \%$ \\
\hline Originality & 91 & 85 & 98 & 94 & 93 & 89 & 98 & 79 & 90 & 97 & $91 \%$ \\
\hline Smartness & 84 & 86 & 97 & 98 & 92 & 79 & 98 & 79 & 78 & 89 & $88 \%$ \\
\hline Ease of handle & 86 & 79 & 94 & 92 & 87 & 82 & 99 & 82 & 75 & 91 & $87 \%$ \\
\hline Ordinariness & 90 & 69 & 84 & 91 & 83 & 76 & 98 & 78 & 87 & 76 & $83 \%$ \\
\hline Ease of filling & 90 & 87 & 98 & 82 & 84 & 76 & 87 & 92 & 86 & 67 & $84 \%$ \\
\hline Showiness & 94 & 90 & 95 & 92 & 85 & 89 & 98 & 89 & 84 & 95 & $91 \%$ \\
\hline Simplicity & 77 & 90 & 89 & 79 & 81 & 81 & 94 & 87 & 92 & 77 & $84 \%$ \\
\hline Decorativeness & 72 & 93 & 94 & 93 & 80 & 82 & 82 & 91 & 74 & 61 & $82 \%$ \\
\hline Ease of drinking with & 70 & 80 & 83 & 90 & 85 & 80 & 75 & 84 & 76 & 58 & $78 \%$ \\
\hline Modernity & 87 & 89 & 68 & 99 & 85 & 88 & 91 & 89 & 90 & 95 & $88 \%$ \\
\hline Average for subject & $83 \%$ & $84 \%$ & $91 \%$ & $90 \%$ & $86 \%$ & $83 \%$ & $93 \%$ & $85 \%$ & $85 \%$ & $78 \%$ & \\
\hline
\end{tabular}

Two semantic attributes (Decorativeness, Ease of drinking with) are subjected to a relative inconsistent evaluation (poor value of the average consistency indicator). This may indicate that the group has not a sharp idea of the meaning of these attributes, and that the assessment of the glasses is not easy for them. On the other hand, the consistency indicator is high for attributes Originality and Showiness, which seems to be meaningful for the subjects. These assumptions have been confirmed after the tests by most of the subjects. Let us also note that subject \#10 would gain entering a virtuous loop for improving his consistency of judgment.

Next, in order to infer the meaning of the perceptual axis, and to find which semantic attributes are determinant for the perceptions, the semantic space is mapped onto the perceptual space. This is carried out by a multiple regression, using the perceptual axes as independent variables and the semantic attribute as the dependent variable. The outputs of this method,

\footnotetext{
${ }^{2}$ The consistency value depends on the number of alternatives under consideration, here $N$, and of the "sparsity" of the matrix (the less comparisons, the higher the consistency).
} 
called PROFIT (for PROperty FITting), are the correlation coefficients and the direction cosines (rescalings of the regression coefficients). Table 5 gives the result of these multiple regressions (determination coefficient $\mathrm{R}^{2}$, statistics $\mathrm{F}$ ). The attributes for which the multiple regression is significant (according to Fisher-Snedecor table with P-value $=0.02$ ) are called the determining semantic attributes.

Table 5

Results of the linear regressions of the semantic attributes on the perceptual positioning

\begin{tabular}{|l|c|c|c|}
\hline & $\mathrm{R}^{2}$ & $\mathrm{~F}$ & Significant \\
\hline Stability & 0,54 & 7,06 & yes \\
\hline Fragility & 0,21 & 1,65 & no \\
\hline Quality & 0,12 & 0,84 & no \\
\hline Originality & 0,54 & 7,07 & yes \\
\hline Smartness & 0,71 & 14,9 & yes \\
\hline Ease of handle & 0,74 & 17,81 & yes \\
\hline Ordinariness & 0,50 & 6,01 & yes \\
\hline Ease of filling & 0,46 & 5,14 & no \\
\hline Showiness & 0,60 & 9,34 & yes \\
\hline Simplicity & 0,13 & 0,89 & no \\
\hline Decorativeness & 0,39 & 3,93 & no \\
\hline Ease of drinking with & 0,24 & 1,95 & no \\
\hline Modernity & 0,42 & 4,52 & no \\
\hline
\end{tabular}

It is assumed that the determining semantic attributes play an important role for users' perceptions. The vector model of these attributes is plotted in the perceptual space. The origin of the vector is located arbitrarily in the origin of the frame, the values of the direction cosines give the orientation of the arrow, the arrowhead points in the direction of increasing attribute values and the norm of the vector is proportional to the determination coefficient (figure 6).

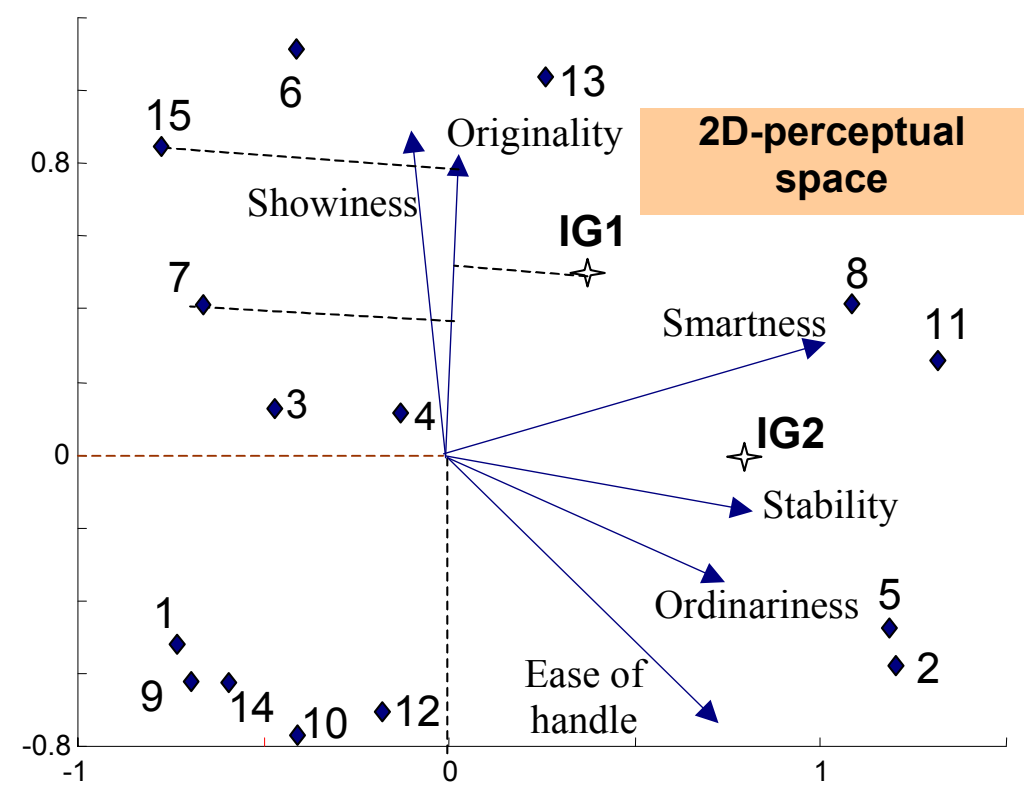

Fig. 6. Perceptual space and the determining semantic attributes (vector model).

\subsection{Definition of the semantic part of the need}

The specification of the semantic part of the need for a new product is performed in two stages.

First, a perceptual positioning of the "ideal" (glass) product, further named IG, is proposed in the perceptual space. This "ideal product" (classical concept in value analysis or in TRIZ 
theory (Savransky, 2000) is a way to figure out a perfect materialization of the new product. The perceptual relative positioning of IG, proposed by the company or the product supervisor, is automatically graphically visualized so as to allow the market and design engineers to reason. The use of perceptual maps is carried out by taking the following considerations into account (Kaul and Rao, 1995):

- avoiding the cannibalization of the products in the company portfolio, and attempting to fight against a competitor,

- determining which products the new glass is perceptually close to,

- evaluating the determining semantic attributes of the new product, in order to control its perceptual positioning. The vector model is used so as to roughly define what kind of product the company is willing to develop, and assist the specification.

Secondly, the specifications of the new glass IG are proposed by comparison with the existing set of glasses. This is one of the strong point of the methodology. It is easy and intuitive to give specifications by comparisons, particularly when we have to deal with semantic attributes. For example, an absolute value of "originality" equal to 8/10 does not make much sense. On the other hand, a specification of "originality" formulated as "less original than glass \#8 but much more than \#2" is interesting and more easily understandable. A group session is particularly suitable for this specification stage, where each participant may bring a particular light on what could be the ideal product. The perceptual space and the vector models here provide a convenient support for discussions.

Technically speaking, for each semantic attribute, the ideal product is compared to the existing set of glasses: A new row and a new column are then added to the pairwise comparison matrix, established in stage 4. But our chosen PC method allows to omit some comparisons when no particular specification has to be made. Again this last facility strengthens the flexibility of our methodology. In order to control the perceptual positioning, the vector model can be used to suggest a relative rank of the ideal product according to the different determining semantic attributes.

It has to be noted that an efficient way to control and predict the perceptual positioning of a new product accurately is to control its performances carefully according to the determining semantic attributes. But this classical marketing technique is subject to shortcomings in the case of very innovative products. Indeed, one must keep in mind that the predictive power of the linear model (PROFIT) may,in certain cases, be very low, because the models have been established on the basis of a set of given products, and could hence be little accurate when used with a new innovative product. This can even be a track to stimulate innovation ${ }^{3}$. Nevertheless, we consider here that the perceptual space and the linear models are valid for a new design.

We suppose that two projects of new glasses are defined, leading to two specification vectors IG1 and IG2. The general orientations for these projects are:

Project \#1: A creative and original glass, for occasional use, which suggests a feeling of sturdiness (solidity), but neither massive nor rough. After extending the PC matrices, a computation of the new scores, given in table 6 , is performed. The corresponding positioning IG1 (for Ideal Glass) is proposed in figure 6. For the attribute "originality" for example, the vector model indicates clearly that the originality of "IG1" is "less than \#15 but more than \#7".

Project \#2: A very functional glass, multi-usage, but not cheap, for standard usage, very stable, with an obvious quality, easy to drink with and easy to handle. The corresponding positioning IG2 is proposed in figure 6.

Firstly, we will only deal with project \#1. We can observe that the fact to introduce the IG1 ideal product in the $R$ PC matrices changes the scores (compare table 3 and table 6), since the

\footnotetext{
${ }^{3}$ For example, according to figure 6 , it could be interesting to try to design a new glass with a high score in originality and a low score in showiness.
} 
scores now sum up to $100 \%$ over the $N+1$ products (including IG1). More importantly, the scores of the $N$ initial products did not change in proportions only. Consequently, it may occur that the introduction of IG1 in PC matrices implies rank reversals of some product scores for a given semantic attribute. This issue will be discussed in section 5 .

Table 6

Scores of products relative to semantic attributes for the initial set of glasses and ideal glass IG1

\begin{tabular}{|l|c|c|c|c|c|c|c|c|c|c|c|c|c|c|c|c|}
\hline \multicolumn{1}{|c|}{ Scores (\%) } & $\mathbf{1}$ & $\mathbf{2}$ & $\mathbf{3}$ & $\mathbf{4}$ & $\mathbf{5}$ & $\mathbf{6}$ & $\mathbf{7}$ & $\mathbf{8}$ & $\mathbf{9}$ & $\mathbf{1 0}$ & $\mathbf{1 1}$ & $\mathbf{1 2}$ & $\mathbf{1 3}$ & $\mathbf{1 4}$ & $\mathbf{1 5}$ & $\mathbf{I G 1}$ \\
\hline Stability & 5,6 & 7,9 & 4,5 & 4,5 & 7,3 & 5,9 & 5,7 & 7,7 & 4,0 & 4,3 & 12,1 & 5,3 & 5,5 & 6,6 & 6,8 & 6,6 \\
\hline Fragility & 6,9 & 8,1 & 7,0 & 4,4 & 3,3 & 10,5 & 5,5 & 4,6 & 5,3 & 6,4 & 7,6 & 5,6 & 5,5 & 4,9 & 9,2 & 5,3 \\
\hline Quality & 5,7 & 7,8 & 4,5 & 7,8 & 5,3 & 7,1 & 8,3 & 5,7 & 4,6 & 4,3 & 6,5 & 6,6 & 4,4 & 5,9 & 10,1 & 5,3 \\
\hline Originality & 4,3 & 7,1 & 6,4 & 5,3 & 4,3 & 8,4 & 6,4 & 4,2 & 4,0 & 4,7 & 4,7 & 4,8 & 13,0 & 4,6 & 9,7 & 8,2 \\
\hline Smartness & 5,0 & 4,3 & 4,2 & 6,5 & 3,5 & 10,1 & 9,3 & 5,3 & 4,8 & 6,4 & 3,7 & 4,5 & 10,6 & 4,7 & 14,7 & 2,2 \\
\hline Ease of handle & 3,5 & 8,9 & 4,3 & 5,8 & 9,1 & 4,2 & 4,3 & 8,5 & 4,3 & 3,4 & 9,8 & 9,1 & 8,8 & 4,4 & 5,0 & 6,8 \\
\hline Ordinariness & 7,0 & 11,8 & 3,8 & 4,6 & 11,9 & 3,2 & 5,7 & 9,4 & 4,4 & 3,7 & 5,9 & 4,4 & 6,5 & 6,9 & 6,4 & 4,3 \\
\hline Ease of filling & 4,7 & 6,5 & 3,4 & 5,3 & 7,2 & 4,0 & 5,0 & 8,1 & 7,1 & 3,3 & 13,3 & 7,0 & 9,4 & 6,6 & 4,4 & 4,7 \\
\hline Showiness & 5,0 & 5,1 & 9,5 & 6,9 & 4,3 & 10,9 & 5,1 & 3,4 & 4,4 & 5,9 & 4,0 & 2,8 & 9,9 & 5,7 & 9,6 & 7,5 \\
\hline Simplicity & 7,2 & 8,9 & 5,7 & 6,5 & 10,2 & 7,4 & 6,3 & 7,1 & 5,5 & 4,8 & 4,0 & 4,4 & 6,9 & 5,3 & 7,5 & 2,2 \\
\hline Decorativeness & 5,9 & 5,1 & 5,2 & 5,5 & 3,9 & 8,0 & 5,4 & 4,8 & 3,8 & 7,8 & 4,3 & 7,4 & 11,4 & 3,7 & 11,5 & 6,4 \\
\hline Ease of drinking with & 4,1 & 7,0 & 4,9 & 5,7 & 8,0 & 5,9 & 4,4 & 7,1 & 5,2 & 4,0 & 10,8 & 5,9 & 4,2 & 6,8 & 10,7 & 5,3 \\
\hline Modernity & 8,1 & 3,3 & 7,7 & 6,4 & 3,4 & 5,9 & 5,8 & 3,3 & 3,5 & 6,1 & 3,7 & 4,0 & 13,1 & 9,7 & 11,8 & 4,2 \\
\hline
\end{tabular}

The IG1 vector is considered as a target for the development of a new product. But a new product prototype will not match all the targeted values of the semantic attributes. The relative importance of the semantic attributes must then be considered to weight the differences from the targeted values and to be able to calculate a multi-criteria mark. This step is classical in value analysis where the importance of functions is weighted. The corresponding pairwise $R \times R$ comparison matrix is given table 7, with the resulting weights of the semantic attributes $w_{i}$ in the last column.

Table 7

Pairwise comparison matrix between the semantic attributes for project \#1 and the resulting weight vector (right column)

\begin{tabular}{|c|c|c|c|c|c|c|c|c|c|c|c|c|c|c|}
\hline $\begin{array}{r}\text { PROJECT \#1 } \\
\ll \text { creative glass }\end{array}$ & 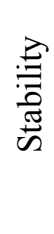 & 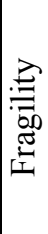 & 忌 & 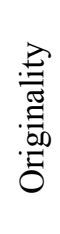 & 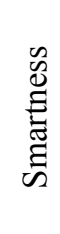 & 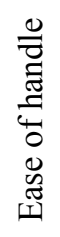 & 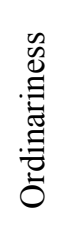 & 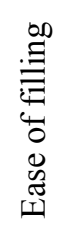 & 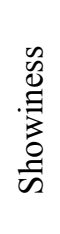 & 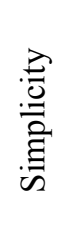 & 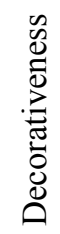 & 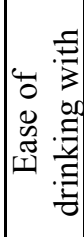 & 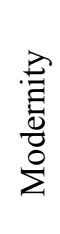 & 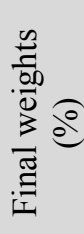 \\
\hline Stability & & & & $<<$ & & & $<<$ & & & $<<$ & & & $<$ & 1,8 \\
\hline Fragility & & & & $<$ & & $>>$ & $<\sim$ & $>$ & & $>\sim$ & $>$ & $>\sim$ & & 8,3 \\
\hline Quality & & & & $<\sim$ & & & $=$ & & & & & & & 14,3 \\
\hline Originality & & & & & $>_{\sim}$ & $>>$ & $=$ & $>>$ & $>>$ & $>$ & $>>$ & $>>$ & $>\sim$ & 20,6 \\
\hline Smartness & & & & & & & $=$ & & & & & & & 10,1 \\
\hline Ease of handle & & & & & & & $<<$ & & & & & & & 1,5 \\
\hline Ordinariness & & & & & & & & & $>>$ & & $>>$ & $>$ & $>\sim$ & 14,9 \\
\hline Ease of filling & & & & & & & & & & & & & & 3 \\
\hline Showiness & & & & & & & & & & & $=$ & $>$ & & 2,9 \\
\hline Simplicity & & & & & & & & & & & & & & 8,5 \\
\hline Decorativeness & & & & & & & & & & & & & & 2,3 \\
\hline Ease of drinkin & & & & & & & & & & & & & & 2,8 \\
\hline Modernity & & & & & & & & & & & & & & 9 \\
\hline
\end{tabular}

\subsection{Design stage}

Two prototypes (a real and a virtual glass) are proposed as candidates for the new design of project \#1 (figure 7). 

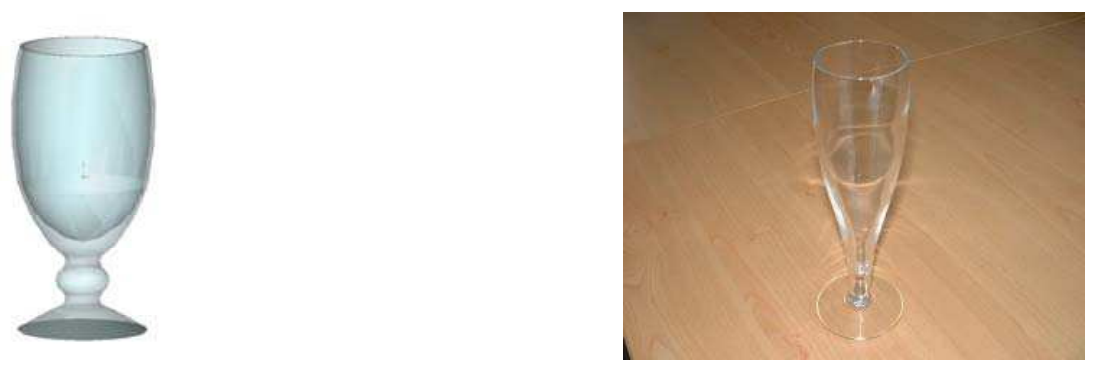

Fig. 7. Candidate glasses for the new design: N1 (right) and N2 (left)

\subsection{Assessment of the candidate products}

The new glasses $\mathbf{N} 1$ and $\mathbf{N} 2$ are added to the pairwise comparison matrices and relative assessments to the $N$ initial glasses are provided by the subjects, exactly as was performed for the ideal product IG. After computation, the new relative scores are given in table 8 . Note that the scores have changed for the initial set of glasses since they add up to $100 \%$ for all the glasses, including IG1, N1 and N2.

Table 8

Evaluation of the glasses

\begin{tabular}{|l|c|c|c|c|c|c|c|c|c|c|r|r|r|r|r||r||r|r|}
\hline \multicolumn{1}{|c|}{ scores (\%) } & $\mathbf{1}$ & $\mathbf{2}$ & $\mathbf{3}$ & $\mathbf{4}$ & $\mathbf{5}$ & $\mathbf{6}$ & $\mathbf{7}$ & $\mathbf{8}$ & $\mathbf{9}$ & $\mathbf{1 0}$ & $\mathbf{1 1}$ & $\mathbf{1 2}$ & $\mathbf{1 3}$ & $\mathbf{1 4}$ & $\mathbf{1 5}$ & $\mathbf{I G 1}$ & $\mathbf{N 1}$ & $\mathbf{N 2}$ \\
\hline Stability & 5,0 & 7,0 & 4,0 & 4,0 & 6,5 & 5,3 & 5,1 & 6,9 & 3,6 & 3,9 & 10,9 & 4,8 & 5,0 & 5,9 & 6,1 & 5,9 & 4,9 & 5,4 \\
\hline Fragility & 6,3 & 7,3 & 6,3 & 3,9 & 3,0 & 9,5 & 4,9 & 4,1 & 4,8 & 5,8 & 6,8 & 5,0 & 5,0 & 4,5 & 8,3 & 4,8 & 4,8 & 4,8 \\
\hline Quality & 5,2 & 7,1 & 4,1 & 7,1 & 4,8 & 6,5 & 7,6 & 5,2 & 4,2 & 4,0 & 6,0 & 6,0 & 4,0 & 5,4 & 9,2 & 4,8 & 4,8 & 3,9 \\
\hline Originality & 3,8 & 6,3 & 5,7 & 4,7 & 3,8 & 7,5 & 5,8 & 3,7 & 3,6 & 4,2 & 4,2 & 4,3 & 11,7 & 4,2 & 8,6 & 7,3 & 5,8 & 4,9 \\
\hline Smartness & 4,8 & 4,1 & 4,0 & 6,2 & 3,4 & 9,7 & 8,9 & 5,1 & 4,6 & 6,1 & 3,5 & 4,3 & 10,2 & 4,5 & 14,0 & 2,1 & 2,1 & 2,1 \\
\hline Ease of handle & 3,2 & 8,1 & 3,9 & 5,3 & 8,3 & 3,8 & 3,9 & 7,8 & 3,9 & 3,1 & 9,0 & 8,3 & 8,1 & 4,0 & 4,6 & 6,2 & 4,1 & 4,1 \\
\hline Ordinariness & 6,5 & 10,9 & 3,5 & 4,3 & 11,1 & 3,0 & 5,3 & 8,8 & 4,1 & 3,4 & 5,5 & 4,1 & 6,1 & 6,4 & 6,0 & 4,0 & 3,0 & 4,0 \\
\hline Ease of filling & 4,3 & 6,0 & 3,1 & 4,9 & 6,6 & 3,7 & 4,6 & 7,4 & 6,5 & 3,1 & 12,2 & 6,5 & 8,7 & 6,1 & 4,1 & 4,3 & 3,2 & 4,8 \\
\hline Showiness & 4,4 & 4,5 & 8,3 & 6,1 & 3,8 & 9,6 & 4,5 & 3,0 & 3,9 & 5,2 & 3,5 & 2,4 & 8,7 & 5,0 & 8,5 & 6,6 & 6,6 & 5,7 \\
\hline Simplicity & 6,8 & 8,4 & 5,4 & 6,2 & 9,7 & 7,0 & 6,0 & 6,7 & 5,2 & 4,6 & 3,8 & 4,2 & 6,5 & 5,0 & 7,1 & 2,1 & 2,1 & 3,2 \\
\hline Decorativeness & 5,4 & 4,7 & 4,7 & 5,0 & 3,5 & 7,3 & 4,9 & 4,4 & 3,4 & 7,0 & 3,9 & 6,7 & 10,3 & 3,3 & 10,5 & 5,8 & 4,8 & 4,4 \\
\hline Ease of drink. & 3,7 & 6,3 & 4,4 & 5,2 & 7,2 & 5,4 & 4,0 & 6,4 & 4,7 & 3,6 & 9,8 & 5,3 & 3,8 & 6,2 & 9,7 & 4,8 & 4,8 & 4,8 \\
\hline Modernity & 7,4 & 3,1 & 7,0 & 5,8 & 3,1 & 5,4 & 5,3 & 3,0 & 3,2 & 5,5 & 3,4 & 3,6 & 12,0 & 8,9 & 10,8 & 3,9 & 3,9 & 4,8 \\
\hline
\end{tabular}

\subsection{Rating and ranking of the products}

The first step of a product rating process is to calculate, for each semantic attribute, the "closeness" between the score of the product to rate and the score of the ideal product. The closer the two scores, the higher the grade relative to a semantic attribute. For each attribute we have defined a value which represents the "closeness" between a given product and the ideal product, and called this quantity "satisfaction". Three types of satisfaction curves are proposed in figure 8, which represent the three main specification types for an attribute:

- Typel means that the ideal score (given in column "IG1" of table 8 and named $\mathrm{IG}_{\mathrm{i}}$ in figure 8 ) is considered as a minimum value,

- Type 2 means that the ideal score is considered as a maximum value,

- Type 3 means that the ideal score is considered as a target value.

For all three specification types, the maximum satisfaction (i.e. 1) is reached when the product score perfectly matches the ideal score. For each specification, additional parameters must be defined with great attention. They are the $\mathrm{x} \%$ and $\mathrm{y} \%$ parameters appearing in figure 8 that allow the definition of limits of validity or flexibility, classical in functional analysis. 
1

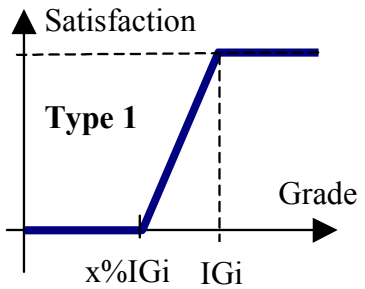

1

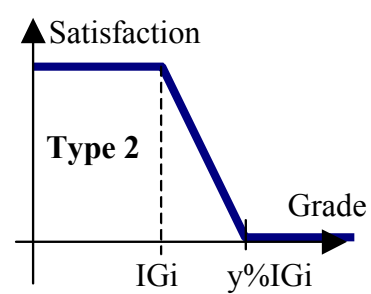

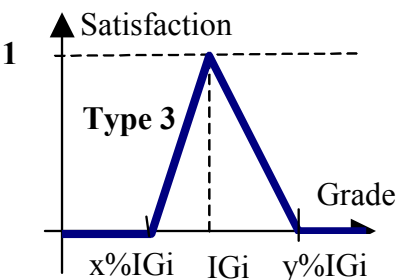

Fig. 8. Definition of the 3 types of satisfaction curves

Here, we suggest that the 2 semantic attributes (Decorativeness, Ease of drinking with) which were previously ticked as the least reliable to get consistent comparisons (low PC consistency) be assigned with looser limits of validity $\mathrm{x} \%$ and $\mathrm{y} \%$. On the other hand, we propose tight values of $\mathrm{x} \%$ and $\mathrm{y} \%$ for the semantic attributes with indicators of high value of consistency (Originality and Showiness). The subjects subscribed to this proposal that formalized their intuitions about the confidence they could have for accurately specifying targets on some dimensions.

Finally, the complete specification of a new glass for project \#1 is given in table 9.

Table 9

Specification of a new glass in project \#1

\begin{tabular}{|c|c|c|c|c|c|}
\hline $\begin{array}{c}\text { SPECIF. } \\
\text { PROJECT\#1 }\end{array}$ & weights & IG1 & Type & $\mathbf{x \%}$ & $\mathbf{y} \%$ \\
\hline Stability & 1,8 & 5,9 & 1 & $70 \%$ & $/$ \\
\hline Fragility & 8,3 & 4,8 & 3 & $70 \%$ & $130 \%$ \\
\hline Quality & 14,3 & 4,8 & 1 & $70 \%$ & $/$ \\
\hline Originality & 20,6 & 7,3 & 3 & $80 \%$ & $120 \%$ \\
\hline Smartness & 10,1 & 2,1 & 3 & $70 \%$ & $130 \%$ \\
\hline Ease of handle & 1,5 & 6,2 & 1 & $70 \%$ & $/$ \\
\hline Ordinariness & 14,9 & 4,0 & 2 & $/$ & $130 \%$ \\
\hline Ease of filling & 3 & 4,3 & 1 & $70 \%$ & $/$ \\
\hline Showiness & 2,9 & 6,6 & 3 & $80 \%$ & $120 \%$ \\
\hline Simplicity & 8,5 & 2,1 & 3 & $70 \%$ & $130 \%$ \\
\hline Decorativeness & 2,3 & 5,8 & 3 & $50 \%$ & $150 \%$ \\
\hline Ease of drink. & 2,8 & 4,8 & 1 & $50 \%$ & $/$ \\
\hline Modernity & 9 & 3,9 & 3 & $70 \%$ & $130 \%$ \\
\hline
\end{tabular}

Starting from the product scores (for products 1 to 15 , plus $N 1$ and N2, see table 8) and from the specification of project \#1, satisfaction scores are calculated in a satisfaction table (table 10) through a basic spreadsheet. Note that obviously IG1 obtains satisfaction grades of 1 everywhere. For the final grade of each product, a multicriteria evaluation following the A.H.P. process is adopted. Let $S_{i j}$ be the satisfaction for semantic attribute $i$ and product $j$ (given in table 10), the A.H.P. theory requires that the satisfaction scores be normalized over the products. This is given by the formula:

$$
\bar{S}_{i j}=S_{i j} / \sum_{j=1}^{N} S_{i j}
$$

Let $w_{i}$ be the relative weight of semantic attribute $i, R$ the number of attributes: The final evaluation of product $j$, grade( $j)$, is given by:

$$
\operatorname{grade}(j)=\sum_{i=1}^{R} w_{i} \bar{S}_{i j}
$$


A rank of the products can then be established, the ideal product being of course ranked number one (table 10). The new design N1 (ranked $2^{\circ}$ ) represents a satisfactory answer to project\#1 according to the group. Glass $\mathbf{N} 2$ (ranked $4^{\circ}$ ) could be improved. Table 10 shows that glass $\mathbf{N} 2$ could be improved according to the semantic attributes quality, originality, showiness and simplicity for example. Various propositions can be made with CAD systems and virtual prototyping during group sessions.

Table 10

Satisfaction scores and final rank of the glasses

\begin{tabular}{|c|c|c|c|c|c|c|c|c|c|c|c|c|c|c|c|c|c|c|}
\hline $\begin{array}{c}\text { Satisfaction } \\
\text { Sij }\end{array}$ & 1 & 2 & 3 & 4 & 5 & 6 & 7 & 8 & 9 & 10 & 11 & 12 & 13 & 14 & 15 & IG1 & N1 & N2 \\
\hline Stability & 0,5 & 1 & 0 & 0 & 1 & 0,65 & 0,55 & 1 & 0 & 0 & 1 & 0,38 & 0,47 & 1 & 1 & 1 & 0,44 & 0,72 \\
\hline ragility & 0 & 0 & 0 & 0,42 & 0 & 0 & 0,89 & 0,55 & 0,99 & 0,31 & 0 & 0,83 & 0,85 & 0,78 & 0 & 1 & 1 & 1 \\
\hline Quality & 1 & 1 & 0,53 & 1 & 0,99 & 1 & 1 & 1 & 0,57 & 0,4 & 1 & 1 & 0,41 & 1 & 1 & 1 & 1 & 0,33 \\
\hline Orig & 0 & 0,34 & 0 & 0 & 0 & 0,83 & 0 & 0 & 0 & 0 & 0 & 0 & 0 & 0 & 0,06 & 1 & 0 & 0 \\
\hline Sma & 0 & 0 & 0 & 0 & 0 & 0 & 0 & 0 & 0 & 0 & 0 & 0 & 0 & 0 & 0 & 1 & 1 & 1 \\
\hline Ease & 0 & 1 & 0 & 0,53 & 1 & 0 & 0 & 1 & 0 & 0 & 1 & 1 & 1 & 0 & 0,14 & 1 & 0 & 0 \\
\hline Ord & 0 & 0 & 1 & 0,79 & 0 & 1 & 0 & 0 & 0,96 & 1 & 0 & 0,93 & 0 & 0 & 0 & 1 & 1 & 1 \\
\hline Ease & 1 & 1 & 0,06 & 1 & 1 & 0,51 & 1 & 1 & 4 & 0,05 & 1 & 1 & 1 & 1 & 0,84 & 1 & 0,17 & 1 \\
\hline Sho & 0 & 0 & , & 0,62 & 0 & 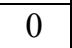 & 0 & 0 & 0 & 0 & 0 & 0 & 0 & 0 & 0 & 1 & 1 & 0,29 \\
\hline Sim & 0 & 0 & 0 & 0 & 0 & 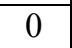 & 0 & $\sigma$ & 0 & 0 & 0 & 0 & 0 & $\sigma$ & 0 & 1 & 1 & 0 \\
\hline Decorativeness & 0,85 & 0,61 & 0,62 & 0,72 & 0,21 & 0,49 & 0,69 & 0,52 & 0,19 & 0,57 & 0,34 & 0,68 & 0 & 0,15 & 0 & 1 & 0,67 & 0,5 \\
\hline Ease of drink. & 0,56 & 1 & 0,84 & 1 & 1 & 1 & 0,65 & 1 & 0,94 & 0,48 & 1 & 1 & 0,56 & 1 & 1 & 1 & 1 & 1 \\
\hline Modernity & 0 & 0,31 & 0 & 0 & 0,32 & 0 & 0 & 0,25 & 0,46 & 0 & 0,62 & 0,79 & 0 & 0 & 0 & 1 & 1 & 0,17 \\
\hline $\operatorname{grade}(\mathbf{j})$ & 1,5 & 5,5 & 2,5 & 4,0 & 2,3 & 10,8 & 2,4 & 2,8 & 4,4 & 2,6 & 2,9 & 5,6 & 1,8 & 2,3 & 2,1 & 24,3 & 14,5 & 7,6 \\
\hline rank & $18^{\circ}$ & $6^{\circ}$ & $12^{\circ}$ & $8^{\circ}$ & $14^{\circ}$ & $3^{\circ}$ & $13^{\circ}$ & $10^{\circ}$ & $7^{\circ}$ & $11^{\circ}$ & $9^{\circ}$ & $5^{\circ}$ & $17^{\circ}$ & $15^{\circ}$ & $16^{\circ}$ & $1^{\circ}$ & $2^{\circ}$ & $4^{\circ}$ \\
\hline
\end{tabular}

\section{Application to the assessment of products}

In order to show how the methodology can be used for the assessment of a new project starting from the work carried out for project\#1, we propose to describe the main stages of the assessment of the previously presented project\#2.

Project\#2 corresponds to a very functional glass, multi-usage, but not cheap, for standard usage, very stable, with an obvious quality, easy to drink with and easy to handle (positioning IG2 proposed in figure 6). We suppose that the project supervisor proposes pairwise comparisons between the semantic attributes which, after computation, lead to the following weights (table 11). The comparison between the ideal glass IG2 and the 15 glasses, performed by the group of subjects, has provided the following specification (table 11). For these comparisons, the subjects only have to insert a new row and column (corresponding to IG2) in the $R 15 \times 15$ comparison matrices, and to provide the most obvious comparisons.

Table 11

Specification for project \#2

\begin{tabular}{|c|c|c|c|c|c|}
\hline $\begin{array}{c}\text { SPECIF. } \\
\text { PROJECT\#2 }\end{array}$ & weights & IG2 & Type & $\mathbf{x \%}$ & y\% \\
\hline Stability & 13,3 & 13,2 & 1 & $70 \%$ & $/$ \\
\hline Fragility & 6,1 & 6,3 & 3 & $70 \%$ & $130 \%$ \\
\hline Quality & 10,5 & 9,1 & 1 & $70 \%$ & $/$ \\
\hline Originality & 7,8 & 5,6 & 3 & $80 \%$ & $120 \%$ \\
\hline Smartness & 7,4 & 6,4 & 3 & $70 \%$ & $130 \%$ \\
\hline Ease of handle & 11,1 & 10,8 & 1 & $70 \%$ & $/$ \\
\hline Ordinariness & 11,0 & 11,1 & 2 & $/$ & $130 \%$ \\
\hline Ease of filling & 3,7 & 12,8 & 1 & $70 \%$ & $/$ \\
\hline
\end{tabular}




\begin{tabular}{|c|c|c|c|c|c|}
\hline Showiness & 2,1 & 5,5 & 3 & $80 \%$ & $120 \%$ \\
\hline Simplicity & 6,3 & 9,4 & 3 & $70 \%$ & $130 \%$ \\
\hline Decorativeness & 4,4 & 5,4 & 3 & $50 \%$ & $150 \%$ \\
\hline Ease of drink. & 9,6 & 11,0 & 1 & $50 \%$ & $/$ \\
\hline Modernity & 6,6 & 6,2 & 3 & $70 \%$ & $130 \%$ \\
\hline
\end{tabular}

In this case, the satisfaction scores and the rank of the products are given table 12. Glass $\# 11$ is the most interesting product for this project\#2.

Table 12

Satisfaction scores and final ranking of the glasses for project\#2

\begin{tabular}{|l|c|c|c|c|c|c|c|c|c|c|c|c|c|c|c|c|}
\hline Satisfaction Sij & $\mathbf{1}$ & $\mathbf{2}$ & $\mathbf{3}$ & $\mathbf{4}$ & $\mathbf{5}$ & $\mathbf{6}$ & $\mathbf{7}$ & $\mathbf{8}$ & $\mathbf{9}$ & $\mathbf{1 0}$ & $\mathbf{1 1}$ & $\mathbf{1 2}$ & $\mathbf{1 3}$ & $\mathbf{1 4}$ & $\mathbf{1 5}$ & $\mathbf{I G 2}$ \\
\hline Stability & 0,5 & 1 & 0 & 0 & 1 & 0,65 & 0,55 & 1 & 0 & 0 & 1 & 0,38 & 0,47 & 1 & 1 & 1 \\
\hline Fragility & 0 & 0 & 0 & 0,42 & 0 & 0 & 0,89 & 0,55 & 0,99 & 0,31 & 0 & 0,83 & 0,85 & 0,78 & 0 & 1 \\
\hline Quality & 1 & 1 & 0,53 & 1 & 0,99 & 1 & 1 & 1 & 0,57 & 0,4 & 1 & 1 & 0,41 & 1 & 1 & 1 \\
\hline Originality & 0 & 0,34 & 0 & 0 & 0 & 0,83 & 0 & 0 & 0 & 0 & 0 & 0 & 0 & 0 & 0,06 & 1 \\
\hline Smartness & 0 & 0 & 0 & 0 & 0 & 0 & 0 & 0 & 0 & 0 & 0 & 0 & 0 & 0 & 0 & 1 \\
\hline Ease of handle & 0 & 1 & 0 & 0,53 & 1 & 0 & 0 & 1 & 0 & 0 & 1 & 1 & 1 & 0 & 0,14 & 1 \\
\hline Ordinariness & 0 & 0 & 1 & 0,79 & 0 & 1 & 0 & 0 & 0,96 & 1 & 0 & 0,93 & 0 & 0 & 0 & 1 \\
\hline Ease of filling & 1 & 1 & 0,06 & 1 & 1 & 0,51 & 1 & 1 & 1 & 0,05 & 1 & 1 & 1 & 1 & 0,84 & 1 \\
\hline Showiness & 0 & 0 & 0 & 0,62 & 0 & 0 & 0 & 0 & 0 & 0 & 0 & 0 & 0 & 0 & 0 & 1 \\
\hline Simplicity & 0 & 0 & 0 & 0 & 0 & 0 & 0 & 0 & 0 & 0 & 0 & 0 & 0 & 0 & 0 & 1 \\
\hline Decorativeness & 0,85 & 0,61 & 0,62 & 0,72 & 0,21 & 0,49 & 0,69 & 0,52 & 0,19 & 0,57 & 0,34 & 0,68 & 0 & 0,15 & 0 & 1 \\
\hline Ease of drink. & 0,56 & 1 & 0,84 & 1 & 1 & 1 & 0,65 & 1 & 0,94 & 0,48 & 1 & 1 & 0,56 & 1 & 1 & 1 \\
\hline Modernity & 0 & 0,31 & 0 & 0 & 0,32 & 0 & 0 & 0,25 & 0,46 & 0 & 0,62 & 0,79 & 0 & 0 & 0 & 1 \\
\hline \multicolumn{1}{|c|}{ grade(j) } & 2,6 & 5,6 & 2,4 & 7,7 & 5,2 & 2,4 & 4,9 & 3,0 & 1,4 & 5,7 & 12,5 & 3,6 & 2,1 & 2,5 & 6,1 & 31,0 \\
\hline \multicolumn{1}{c|}{ rank } & $11^{\circ}$ & $6^{\circ}$ & $14^{\circ}$ & $3^{\circ}$ & $7^{\circ}$ & $13^{\circ}$ & $8^{\circ}$ & $10^{\circ}$ & $16^{\circ}$ & $5^{\circ}$ & $2^{\circ}$ & $9^{\circ}$ & $15^{\circ}$ & $12^{\circ}$ & $4^{\circ}$ & $1^{\circ}$ \\
\hline
\end{tabular}

Our integrated framework seems to offer interesting functionalities for the development of products. It can be readily deployed in companies and used at different stages of the designing of new products. Moreover, it is well adapted to knowledge management for marketing and innovation concerns. Indeed, databases can be built and regularly updated to describe the perceptual space of a market segment. It can be done by the marketing department whose job is to scrutinize the market segments related to a particular type of products. On the other hand, this database of existing and assessed products can be used by the design department for the development of a new project. As soon as a new product of the company is commercialized, the database of the initial product may be updated. Once a database of representative commercialized products has been set up, the whole comprehending-specifying-assessing process is little time-consuming and it prompts innovation and discussion within the group of designers. The comprehending-specifying-assessing process basically consists in extending somewhat the score matrices, in an economical way by simple qualitative comparisons to existing products in the database. Of course, all the results dynamically change from one project to another and from one stage to the followings (see tables 3,6 and 8). But all these computations can be easily automated.

Indeed, it has been observed that each time the PC matrices were extended (from table 3 to table 6 when considering ideal product IG1, and from table 6 to table 8 when considering candidate products $\mathbf{N 1}$ and $\mathbf{N 2}$ ), the scores of the initial products were modified in a way that is not proportional. Consequently, the risk is to change the rank of the initial products whenever a new product is considered such as N1 or N2. This issue is well known as the "rank reversal" problem and it is considered as an illogic shortcoming of the AHP theory. It has been well described by Belton for example (Belton, 1986). Different adaptations of the AHP have been proposed so far to limit or to suppress this issue; one undoubtedly has to be aware of its existence, but the detail of a solution to cope with it is beyond the scope of this paper. 


\section{Conclusions}

The purpose of this paper is to present an approach for studying product semantics. The methodology, split up in several stages, is based on users' tests and several classical methods in sensorial analysis and decision theory (multidimensional scaling, semantic differential method, pairwise comparison, A.H.P). We have presented in detail each step of the methodology on a particular example of table glasses, but this method is generic and can be applied to various products.

Starting with the comprehension of the perceptual space of a set of existing products, the first point is that it provides some help to specify requirements for a new product. One of the originality of our work rests on the ability to specify and assess the semantic part of the need for a new product. The methodology proposed allows a solid evaluation of the product semantics, based on the measurements of users' perceptions. It gives a frame for the assessments, and prevents product semantics from being assessed by rule of thumbs. A strong point of our methodology is to allow the specification of product semantics by comparison with existing products. This is a very convenient and meaningful way for the formulation of the need. Our method gives promising results: It is efficient to grasp people's subjective assessments and to integrate them into a decision procedure.

The second point is that it performs a multicriteria subjective evaluation of new design solutions. This allows a better control on the predicted performances of the product. It is a first step for a more rational processing of product semantics. Contrary to Kansei Engineering, the methodology proposed in this paper does not directly consider design elements. But any new considered design is globally and qualitatively assessed through comparisons with previously existing products. This results in a more understandable and easily deployable assessment process. The next step will be to incorporate synthesis tools of products, as in Kansei Engineering approaches (Nagamachi, 1995 and 2002), so as to support the design stage itself.

The third point is that it provides a logical, consistent and grounded frame for the specification and assessment procedures, and it allows a capitalization of subjective evaluations. E.g., the pairwise comparison matrix could serve as a database and be enriched according to new projects. It takes time to complete the tests. Fortunately, the pairwise comparison method used does not require all the comparisons to run, letting believe that our method is easily usable in practice. This evaluation procedure is particularly suitable for group sessions, during which a unique answer of the group is recorded for each comparison, after discussions and negotiations.

\section{References}

Aoussat A., Christofol H., Le Coq M., 2000. The new product design - a transverse approach. Journal of Engineering Design 11 (4), 399-417.

Belton V., 1986. A comparison of the analytic hierarchy process and a simple multi-attribute value function. European Journal of Operational Research 26, 7-21.

Brunswick E., 1952. The conceptual framework of psychology. Chicago, IL. University of Chicago Press.

Chuang M.C., Chang C.C., Hsu S.H., 2001. Perceptual factors underlying user preferences toward product form of mobile phones. International journal of industrial ergonomics 27, 247-258.

De Graan J.G., 1980. Extensions to the multiple criteria analysis of T. L. Saaty. Report National Institute of Water Supply.

Hsiao S.W., 2002. Concurrent design method for developing a new product. International Journal of Industrial Ergonomics 29, 41-55.

Hsiao S.W., Wang H.P., 1998. Applying the semantic transformation method to product form design. Design Studies 19, 309-330. 
Hsu S.H., Chuang M.C., Chang C.C., 2000. A semantic differential study of designers' and users' product form perception. International Journal of Industrial Ergonomics 25, 375391.

Jindo T., Hirasago K., 1995. Development of a design support system for office chairs using 3D graphics. International Journal of Industrial Ergonomics 15, 95-102.

Jindo T., Hirasago K., 1997. Application studies to car interior of Kansei engineering. International journal of industrial ergonomics 19, 105-114.

Kaul A., Rao R.V., 1995. Research for product positioning and design decision: an integrative review. International Journal of Research in Marketing 12, 293-320.

Krippendorff K. and Butter R., 1984. Product semantics: Exploring the symbolic qualities of form. The Journal of the Industrial Designers Society of America, Spring, 4-9.

Limayem F., 2001. Modèles de pondération par les méthodes de tri croisé pour l'aide à la décision collaborative en projet. PhD Thesis, Ecole Centrale Paris.

Lin R., Lin C.Y., Wong J., 1996. An application of multidimensional scaling in product semantics, International Journal of Industrial Ergonomics 18, 193-204.

Lootsma F.A., 1981. Performance evaluation of nonlinear optimization methods via multicriteria decision analysis and via linear model analysis, in Nonlinear Optimization, M.J.D. Powell ed., Press A. Vol. 1, London, 419-453.

Matsuoka Y., 1999. Method for constructing an inverse reasoning system for form generation from product image objectives. Proceedings of ICED99, Vol.1, Munich, 137-142.

Nagamachi M., 1995. Kansei engineering: a new ergonomic consumer-oriented technology for product development. International Journal of Industrial Ergonomics 15, 3-11.

Nagamachi M., 2002. Kansei engineering as a powerful consumer-oriented technology for product development. Applied Ergonomics 33, 289-294.Osgood C.E., Suci G.J., Tannenbaum P.H., 1957. The measurement of meaning, Illinois press.

Popper R. and Heymann H., 1996. Analysing differences among products and panellists by multidimensional scaling. in T.Naes and E.Risvik, Multivariate analysis of data in sensory science, Elsevier, Netherlands.

Quarante D., 2001. Eléments de design industriel, 3ème édition, Polytechnica.

Saaty T.L. and Hu G., 1998. Ranking by the eigenvector versus other methods in the analytical hierarchy process. Applied Mathematical Letter 11 (4), 121-125.

Saaty T.L., 1980, The Analytic Hierarchy Process. McGraw-Hill, New-York.

Savransky S.D., 2000. Engineering of creativity - Introduction to TRIZ Methodology of Inventive Problem Solving. CRC Press.

Shepard R. N., Romney K., Nerlove S. B., 1973. Multidimensional scaling: Theory and applications in the behavioral sciences.", Volume I: Theory, Seminar Press, New York.

Stevens S.S., 1946. On the Theory of Scales of Measurement" Science. 103(2684), 677-680.

Warrel A., 2001. Design syntactics - a contribution towards a theoretical framework for form design. International Conference on Engineering Design ICED 01, Glasgow.

Yannou B., 2002. Toward a web-based collaborative weighting method in project. Proceedings of IEEE Systems Man and Cybernetics, Hammamet, Tunisia, number SMC02-INV-215. 